\section{Análisis del espesor de los tejidos duros en la dentición permanente humana}

\section{Analysis of the thickness of hard tissues in human permanent dentition}

\section{Resumen}

Objetivo. Verificar el espesor de los tejidos duros dentarios en la actualidad. Métodos. Estudio observacional, descriptivo y transversal. Se utilizaron 94 piezas dentarias permanentes naturales y humanas existente en la morfoteca de la facultad de odontología de la Universidad Nacional del Nordeste y recopiladas durante 2004 al 2014, libres de lesiones, restauraciones, con corona y raíz completas. Se seleccionaron ocho muestras de cada grupo (incisivos, caninos, premolares y molares) para medir el espesor de los tejidos duros en los tercios incisal, oclusal, central, cervical y apical. Se utilizó una morsa plana modelo AA y discos de carborundum en micromotor tipo Dremel 4000 para realizar cortes longitudinales en sentido mesiodistal, de cada pieza seleccionada y se procedió a pulir la superficie con piedra pómez hasta obtener el mínimo espesor. La medición se realizó en milímetros con digital microscope, resolution up to $2 \mathrm{M}$ pixel, 25-400x. Resultados. El tejido de mayor espesor en todos los grupos dentarios fue la dentina cuyo valor fue 1,53 $\mathrm{mm}$ a 5,16 mm. Le siguió en orden el esmalte con $0,87 \mathrm{~mm}$ a 3,47 $\mathrm{mm}$ según el lugar de ubicación y el tejido más delgado lo representó el cemento con valores entre $0,18 \mathrm{~mm}$ y $0,78 \mathrm{~mm}$. El mayor espesor de esmalte y dentina fue registrado en el grupo premolar, mientras que el mayor espesor de cemento, en el grupo molar. Conclusión. El trabajo realizado ha permitido observar diferencias significativas en los espesores de los tejidos dentarios, medidos en piezas dentarias permanentes humanas.

Palabras clave: Esmalte dental; Dentina; Cemento (fuente: DeCS BIREME).

\begin{abstract}
Objective. To verify the thickness of dental hard tissues at present. Methods. Observational, descriptive and cross-sectional study. Ninety four human permanent teeth existing in the library of the Faculty of Dentistry of the National Northeast University were collected during 2004-2014, these were free of injuries and restorations, with full crowns and root were used. Eight samples from each group (incisors, canines, premolars, and molars) were selected to measure the thickness of hard tissues of incisal, occlusal, central, cervical, and apical thirds. A Model AA flat vice and carborundum discs were used in a
\end{abstract}

\section{Artículo Original}

\author{
María Constanza Affur 1,a , María Alejandra Gili ${ }^{1, b}$, Gabriela \\ Guadalupe Bessone ${ }^{1, b}$ \\ ${ }^{1}$ Universidad Nacional del Nordeste, UNNE, Corrientes, \\ Argentina. \\ a Especialista en Docencia y Gestión Universitaria en el \\ ámbito de la Salud. \\ ${ }^{\mathrm{b}}$ Doctora en Odontología.
}

\section{Correspondencia:}

Gabriela Guadalupe Bessone: gbessone@odn.unne. edu.ar

Av. Libertad 5450, Facultad de Odontología, Campus Deodoro Roca. 3400 Corrientes - Argentina.

ORCID: 0000-0002-5835-371X

\section{Coautores:}

María Constanza Affur: mcaffur@odn.unne.edu.ar ORCID: 0000-0002-1419-2192

María Alejandra Gili: magili@odn.unne.edu.ar ORCID: 0000-0003-1463-1105

\section{Editor:}

Juan Carlos Cuevas-González Universidad Autónoma de Ciudad Juárez, México.

Conflicto de intereses: los autores declaran no tener conflictos de interés.

Fuente de financiamiento: sin financiamiento.

Recibido: 27/07/20

Aceptado: 06/09/20

Publicado: 16/11/20 
Dremel 4000 micromotor to make longitudinal cuts in the mesiodistal direction of each selected piece and the surface was polished with a pumice stone until minimum thickness was obtained. The measurement was made in millimeters with a digital microscope, resolution up to $2 \mathrm{M}$ pixel, 25 - 400x. Results. The thickest tissue in all the dental groups was dentin whose value was $1.53 \mathrm{~mm}$ to $5.16 \mathrm{~mm}$, enamel followed in order with $0.87 \mathrm{~mm}$ to $3.47 \mathrm{~mm}$ depending on the location, and the thinnest tissue was cement with values between $0.18 \mathrm{~mm}$ and $0.78 \mathrm{~mm}$. The greatest thickness of enamel and dentin was registered in the premolar group, while the greatest thickness of cement, in the molar group. Conclusion. This work has allowed us to observe significant differences in the thickness of the dental tissues, measured in permanent human teeth.

Keywords: Dental enamel; Dentine; Dental cement (source: MeSH NLM).

\section{Introducción}

La anatomía es la ciencia que estudia la forma y las estructuras de los organismos vivos, clasificándose en anatomía macroscópica, que observa las estructuras a simple vista y la anatomía microscópica que utiliza auxiliares ópticos para la observación ${ }^{1}$.

El anatomista italiano Bartolomeo Eustachio (15201574), fundador de la anatomía moderna, publicó en 1562 en su libro Libellus de dentibus, la primera obra dedicada a la anatomía de los dientes, donde describe la morfología, fisiología y formación de estos. Para este autor, la anatomía enfoca el estudio y organización del diente, tanto aislado o como integrante del sistema dentario y del aparato masticatorio, dentro de los cuales establece múltiples y variadas relaciones con los elementos vecinos. Del diente como órgano estudia cómo es, para qué sirve, cuántas denticiones y grupos dentarios existen, qué nomenclatura se utiliza para designar sus componentes y partes, además de analizar la estructura de las piezas dentarias, los tejidos que la componen y las etapas de su desarrollo tanto ontogenético como filogenético ${ }^{2,3}$.

"Aunque la anatomía aparenta ser una ciencia estática, la anatomía dentaria escapa a tal precepto, ante la necesidad de explicar cuál es la razón de la existencia y disposición de las estructuras dentarias.” Mario Figún y Ricardo Garino (2007) ${ }^{4}$. Su estudio requiere del conocimiento de la morfología de las diferentes piezas dentarias que componen la dentición humana y de la relación que existe entre la forma, el color, la estructura y la función. Los dientes son considerados órganos por estar constituidos por diferentes tejidos, de los cuales el esmalte, la dentina y el cemento son duros o mineralizados y la pulpa dentaria es tejido conectivo de variedad laxo ricamente vascularizado e inervado.

El esmalte, llamado también tejido adamantino o sustancia adamantina tiene origen ectodérmico. Cubre a manera de casquete a la dentina en la porción coronaria, y por su translucidez adopta un color blanco amarillento a grisáceo propio de la dentina subyacente. Es considerado el tejido más duro del organismo, debido a que estructuralmente está constituido por prismas altamente mineralizados que lo recorren en todo su espesor, desde la conexión amelodentinaria (CAD) a la superficie externa o libre en contacto con el medio bucal. La dureza del esmalte se debe a que posee un porcentaje muy elevado (95\%) de matríz inorgánica representada por fosfato cálcico formando cristales de hidroxiapatita. En esto, se asemeja a otros tejidos mineralizados como la dentina y el cemento ${ }^{5}$.

En cuanto a su espesor es de $2 \mathrm{~mm}$ en el borde incisal de incisivos y de 2,4 mm en caninos. En la superficie oclusal de premolares y molares adquiere un valor máximo de $3 \mathrm{~mm}^{6}$.

La dentina, llamada también sustancia ebúrnea o marfil, es el eje estructural del diente y constituye el tejido mineralizado que conforma el mayor volumen de la pieza dentaria. Interiormente, la dentina delimita a la cámara pulpar que contiene a la pulpa dental. El tejido pulpar y dentinario conforman estructural, embriológica y funcionalmente una verdadera unidad biológica conocida como complejo dentino-pulpar ${ }^{7}$.

Su espesor aumenta con la edad por actividad normal o patológica. Oscila entre $1,5 \mathrm{~mm}$ y $4,5 \mathrm{~mm}$. EI cemento es un tejido conectivo mineralizado derivado de la capa celular ectomesenquimática del saco dentario. A semejanza del esmalte, el cemento cubre la dentina, aunque sólo en la porción radicular y da anclaje a las fibras del ligamento periodontal ${ }^{5}$.

Su mayor espesor se ubica en el ápice y su mínimo espesor, en el cuello anatómico del diente. Varía entre 80 y 120 micrones ${ }^{8,9}$. Según los autores brasileños (Nunes de Abreu Tunes y Botelho Nogueir, 2012) los espesores de los tejidos son: esmalte 2 a $3 \mathrm{~mm}$, dentina 2 a $5 \mathrm{~mm}$ y el cemento es amplio en los jóvenes y diminuto en los ancianos ${ }^{10}$. Los dientes formados por diferentes tejidos y elementos arquitectónicos similares, varían en su forma, volumen y posición dando origen a los distintos grupos dentarios. Esta agrupación por afinidad de características anatómicas permite distinguir en la dentición temporaria tres grupos dentarios (incisivos, caninos y molares) y en la dentición permanente cuatro grupos, debido a la incorporación de los premolares ${ }^{11}$. Siendo la morfometría dentaria motivo de varias investigaciones realizadas por los docentes de la facultad de odontología de la universidad Nacional del Nordeste, y siguiendo con la línea de investigación se hace necesario verificar el espesor de los tejidos dentarios, con el fin presentar datos actualizados 
que puedan ser contrastados con los publicados por otros investigadores de la anatomía dentaria.

\section{Métodos}

El estudio fue observacional, descriptivo y transversal. Se utilizaron para la muestra 96 piezas dentarias permanentes naturales y humanas existente en la morfoteca de la Cátedra Introducción a la Odontología de la Facultad de Odontología de la Universidad Nacional del Nordeste y recopiladas durante los años 2004 al 2014, libres de lesiones o restauraciones, con corona y raíz completas. No se incluyeron en la muestra, dientes con patologías coronarias y/o radiculares, con lesión o desgaste y raíces con ápices sin calcificar. Las mismas fueron seleccionadas teniendo en cuenta los criterios de inclusión y luego de la selección de incisivos centrales superiores (ICS), incisivos laterales superiores (ILS), incisivos centrales inferiores (ICI), incisivos laterales inferiores (ILI), primeros premolares superiores (PPMS), segundos premolares superiores (SPMS), primeros premolares inferiores (PPMI), segundos premolares inferiores (SPMI), primeros molares superiores (PMS), segundos molares superiores (SMS), terceros molares superiores (TMS), primeros molares inferiores (PMI), segundos molares inferiores (SMI) y terceros molares inferiores (TMI), las piezas dentarias fueron acondicionadas mediante baño de inmersión en partes iguales de agua e hipoclorito de $\mathrm{Na}$ al 5\% durante 24 horas, para luego retirarlas y colocarlas bajo chorro de agua corriente, durante $10 \mathrm{minu}$ tos, con el fin de eliminar todo resto de tejido orgánico o detritus. Una vez realizado el enjuague se colocaron sobre papel absorbente para permitir el secado.

Las piezas seleccionadas se clasificaron por grupo dentario y ubicación en el arco y conservadas en una caja con divisiones y rótulos.

Con el propósito de estimar las dimensiones de los tejidos dentarios se seleccionaron 8 muestras de cada grupo (incisivos, caninos, premolares y molares) para medir el espesor del esmalte, dentina y cemento en los tercios incisal, oclusal, central, cervical y apical. Para ello se utilizó una morsa plana Modelo AA y mediante discos de carborundum montados en micromotor tipo Dremel 4000 se realizaron cortes longitudinales en el tercio medio y en sentido mesiodistal de cada pieza seleccionada. Posteriormente, se procedió a pulir la superficie a evaluar con piedra pómez hasta obtener el mínimo espesor.

La medición de los espesores de los tejidos duros se realizó en milímetros con Digital Microscope, resolution up to $2 \mathrm{M}$ pixel, 25-400x. Los resultados obtenidos fueron registrados a través de imágenes digitales y analizados estadísticamente utilizando el software Infostat versión $1,1^{13}$.

Los valores obtenidos de espesor de esmalte se compararon, mediante una prueba t para una muestra, con los valores establecidos por autores brasileños ${ }^{10}$ quienes establecieron un promedio de 2 a $3 \mathrm{~mm}$. Los valores de dentina observados en la muestra estudiada se compararon, mediante una prueba $t$ para una muestra, con los valores establecidos por Figún y Garino ${ }^{8,9}$ quienes establecieron un promedio de $3 \mathrm{~mm}(1,5$ a $4,5 \mathrm{~mm}$ de espesor), (Figura 1).

\section{Resultados}

La medición de los espesores de los tejidos duros que conforman las piezas dentarias, esmalte, dentina y cemento, han arrojado los siguientes resultados:

El espesor de esmalte obtenido en los diferentes grupos dentarios ha sido mayor en los premolares (Figura 2). El espesor de dentina obtenido en los diferentes grupos dentarios ha sido mayor en los premolares (Figura 3). El espesor de cemento obtenido en los diferentes grupos ha sido mayor en los molares (Figura 4), analizados los espesores de los tejidos por grupos dentarios los resultados fueron:

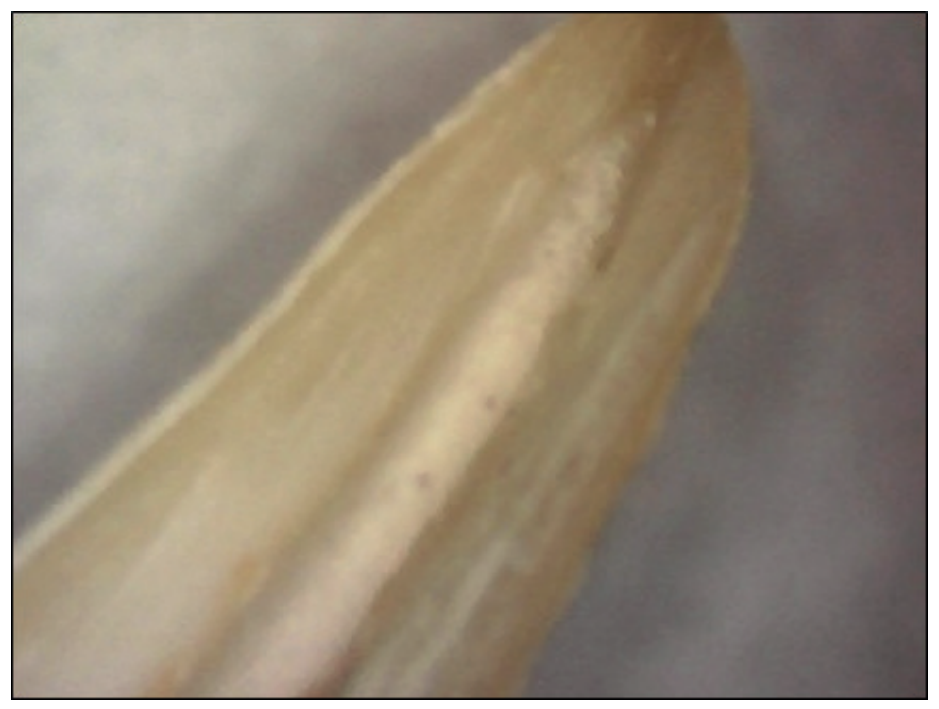

Figura 1. Porción radicular del ICS en corte longitudinal 
Para el grupo incisivos la dentina presentó un valor máximo de 4,53 $\mathrm{mm}$ siendo el tejido con mayor espesor, le sigue en orden el esmalte con valor máximo de 1,74 $\mathrm{mm}$ y el cemento con $0,43 \mathrm{~mm}$ de espesor máximo ( $\mathrm{Fi}$ gura 5). Muestra (Figura 6) la relación en milímetros de los tres tejidos medidos en el grupo caninos, la dentina es el tejido de mayor espesor alcanzando en este grupo un espesor máximo de $4,5 \mathrm{~mm}$, el esmalte de $2,15 \mathrm{~mm}$ y el cemento un valor máximo de $0,45 \mathrm{~mm}$.

En el grupo premolar la dentina es el tejido de mayor espesor alcanzando un valor máximo de $5,2 \mathrm{~mm}$ siguiéndole en orden el esmalte con $3,47 \mathrm{~mm}$ y el cemento con 0,42 mm (Figura 7). En el grupo molar se observa que el tejido con mayor espesor 4,82 es la dentina, le siguen en grosor el esmalte, siendo el tejido más delgado el cemento (Figura 8).

\section{Discusión}

La medición de espesores marcó diferencias con los datos existentes, debido a que los autores Figún y Garino 8,9 , consideran que el esmalte posee $2 \mathrm{~mm}$ en incisivos, 2,4 en caninos y de $3 \mathrm{~mm}$ en la superficie oclusal de premolares y molares. Los anatomistas brasileños ${ }^{10}$,

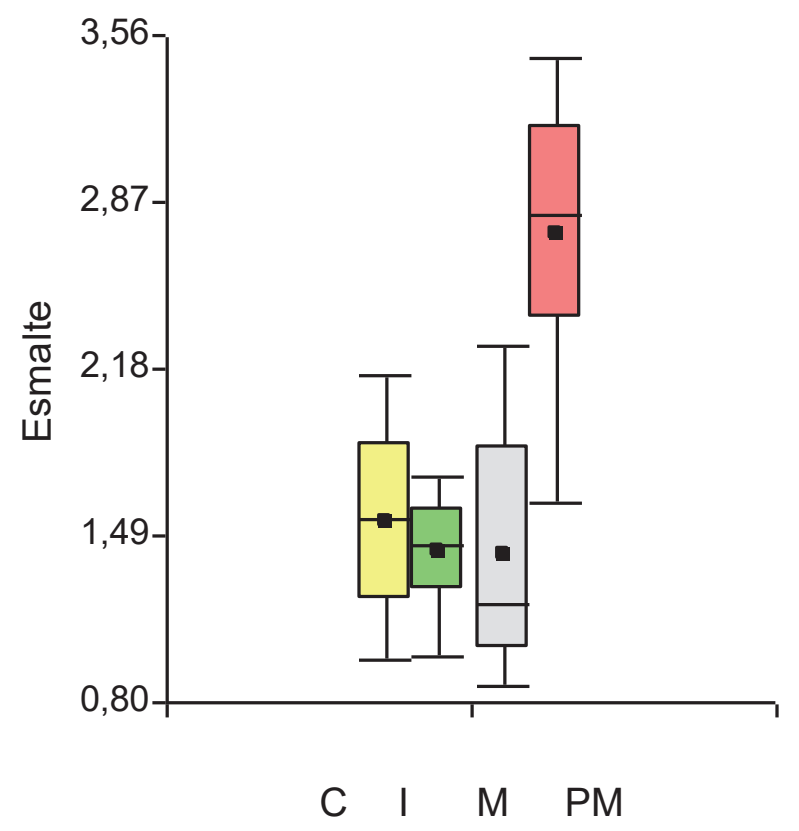

Figura 2. Espesor del esmalte en los grupos dentarios

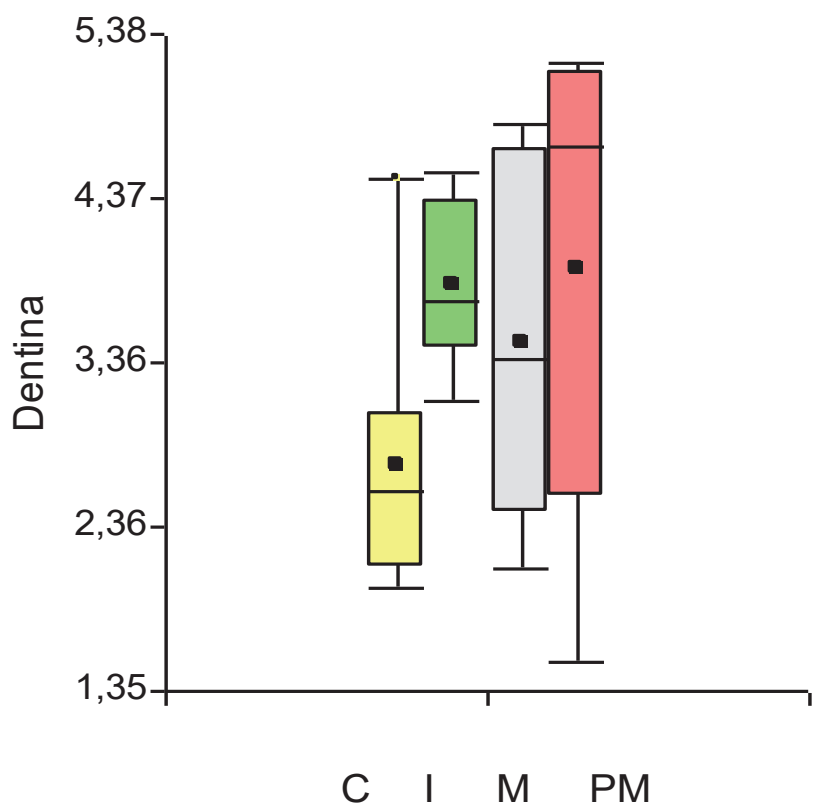

Figura 3. Espesor de la dentina en los grupos dentarios 


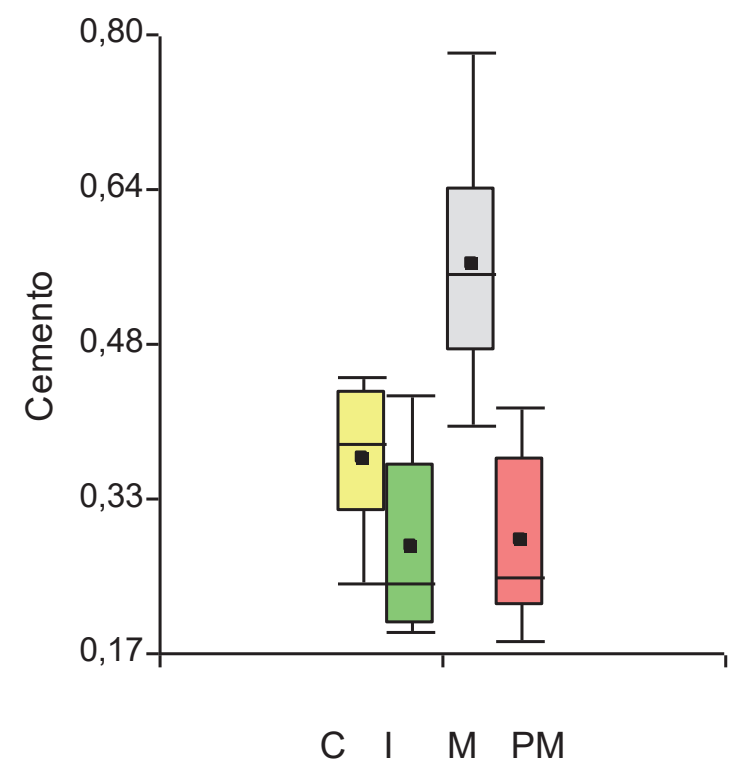

Figura 4. Espesor del cemento en los grupos dentarios

\section{Espesor de los tejidos en grupo Incisivo}

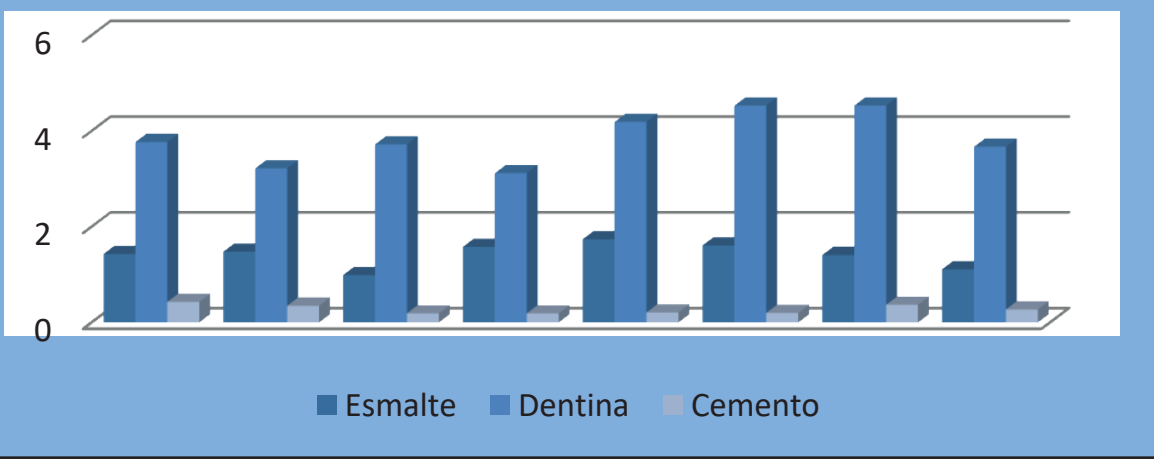

Figura 5. Espesor de los tejidos en grupo Incisivo

\section{Espesor de los tejidos en el grupo Canino}

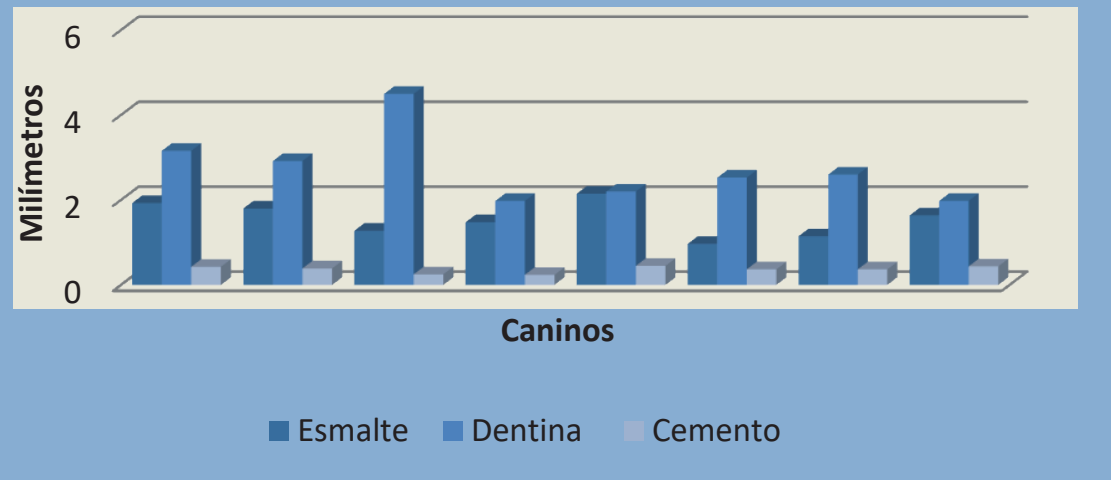

Figura 6. Espesor de los tejidos en el grupo canino 


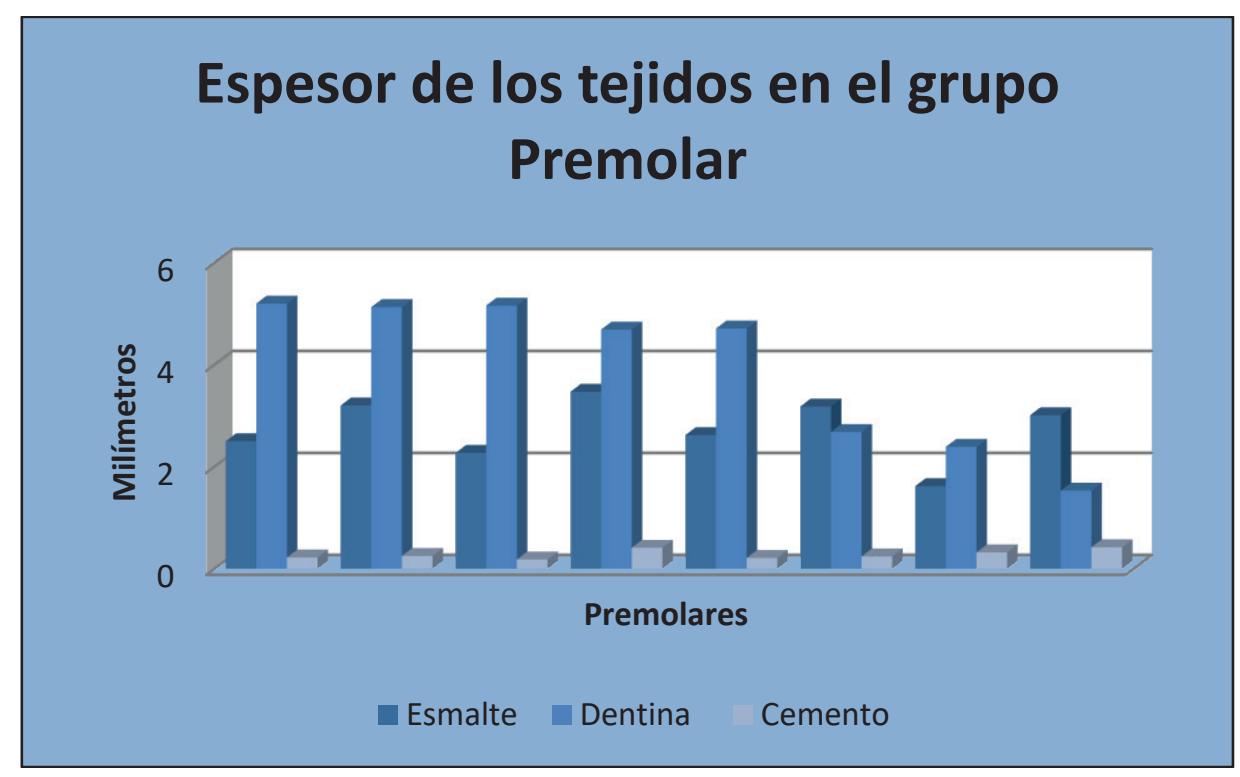

Figura 7. Espesor de los tejidos en el grupo premolar

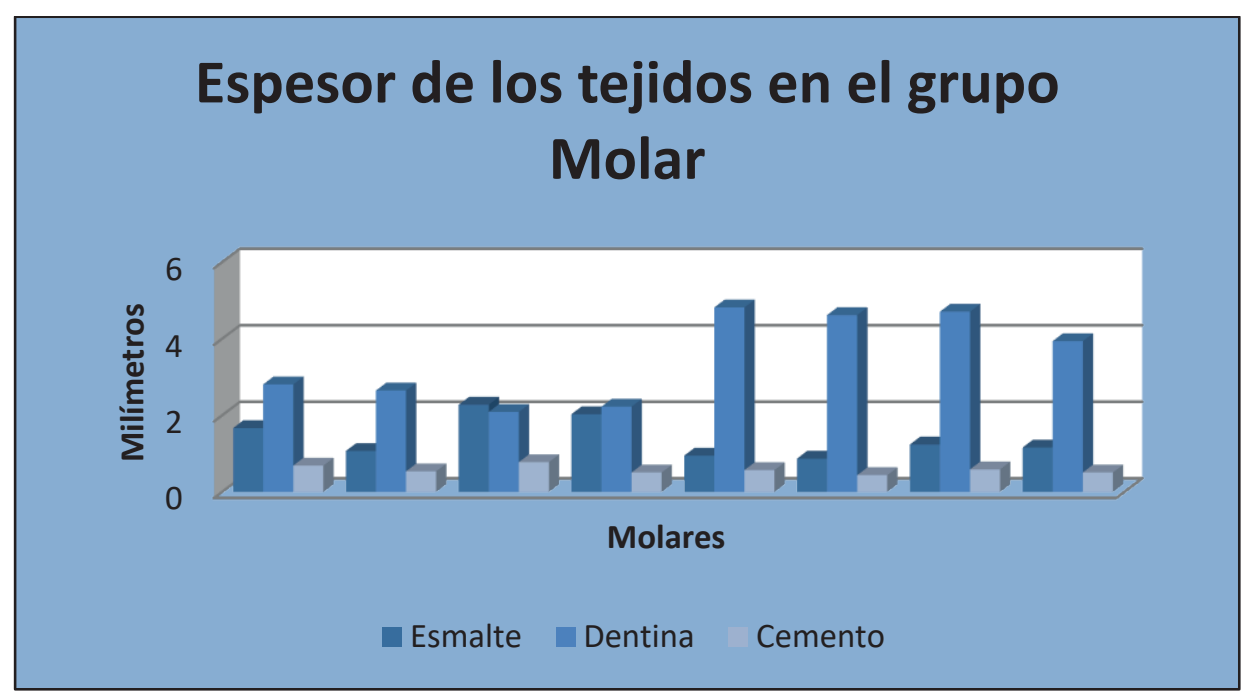

Figura 8. Espesor de los tejidos en el grupo molar

consideran que el espesor varía entre 2 a $3 \mathrm{~mm}$ según su localización. Nuestros resultados han arrojados valores que van entre 0,80 y $3,50 \mathrm{~mm}$ para el espesor de esmalte, dependiendo del lugar donde se han realizado las mediciones. En el tercio cervical aparecen los menores espesores y a nivel de incisal u oclusal, el mayor espesor en relación a este tejido. Asimismo, el mayor espesor en relación a los grupos dentarios fue encontrado en los premolares.

Para el esmalte, la prueba estadística t respecto de un espesor promedio de $2 \mathrm{~mm}$ ha determinado que existe diferencia significativa con los datos hallados t 14,03 y un valor $\mathrm{p}<0,0001$.

Con respecto a la dentina nuestros resultados amplían el rango de valores encontrados, los que oscilan entre $1,5 \mathrm{~mm}$ a $5,15 \mathrm{~mm}$ de espesor y su mayor espesor fue hallado en el grupo de premolares. El espesor asignado a la dentina por Figún y Garino fue de $1,5 \mathrm{~mm}$ a 4,5 $\mathrm{mm}$. Al comparar los datos obtenidos respecto de un promedio de $3 \mathrm{~mm}$ las pruebas mostraron diferencias estadísticamente significativas con valores de t 17,67 y un valor $\mathrm{p}<0,0001$.

El cemento resultó ser el tejido dentario de menor espesor en coincidencia con los anatomistas ${ }^{18}$, sin encontrar valores que los representen, en cambio este trabajo ha permitido la definición de su espesor en los dientes permanentes humanos con valores que se encuentran entre 0,10 y $0,80 \mathrm{~mm}$ y cuyo mayor espesor fue observado en el grupo de los molares.

El trabajo realizado ha permitido observar diferencias significativas en los espesores de los tejidos dentarios, medidos en piezas dentarias permanentes humanas.

Resulta interesante destacar que el tejido de mayor espesor en todos los grupos dentarios fue la dentina cuyo valor varía entre $1,53 \mathrm{~mm}$ a $5,16 \mathrm{~mm}$. Le siguió en 
orden el esmalte, cuyos valores oscilaron entre $0,87 \mathrm{~mm}$ a 3,47 mm según el lugar de ubicación y el tejido más delgado lo representó el cemento cuyos valores oscilaron entre $0,18 \mathrm{~mm}$ y $0,78 \mathrm{~mm}$.

Asimismo, el mayor espesor del esmalte y la dentina fue registrado en el grupo premolar, mientras que el mayor espesor de cemento fue hallado en el grupo molar.

\section{Referencias bibliográficas}

1. Brúel A, Christensen E, Tranum Jensen J, Geneser F. Histología. 4ta ed. México: Panamericana; 2014.

2. Velayos JL. Anatomía de la Cabeza para Odontólogos. 4ta ed. Panamericana 2007.

3. Ash M, Nelson S. Wheeler. Anatomía Fisiología y Oclusión Dental. Elservier. España 2004.

4. Figún M, Garino R. Anatomía Odontológica Funcional y Aplicada. El Ateneo 2007 2a.Ed.

5. Avery JK, Chiego DJ. Principios de Histología y Embriología Bucal. $3^{\circ}$ ed. Editorial Elsevier. Madrid, España. 2007

6. Madeira MC. Anatomia Do Dente. São Paulo: Sarvier, 2000.

7. Gómez de Ferraris ME, Campos Muñoz A. Histología, Embriología e Ingeniería Tisular Bucodental. 3ra ed. Madrid, España: Editorial Médica Panamericana; 2009.

8. Figún M, Garino R: Anatomía Odontológica Funcional y Aplicada. El Ateneo. Argentina 2002.

9. Figún M. Garino R. Anatomía Odontológica Funcional y Aplicada. El Ateneo 2010 2a.Ed. 13º reimpresión.
10. Nunes De Abreu Tunes G, Botelho Nogueira C. Introdução ao Estudo da Anatomía. Etec Philadelho Gouvêa Netto Prótese Dentária - 2012.

11. Carbó Ayala, J. Anatomía Dental y de la Oclusión. Editorial Ciencias Médicas. La Habana. 2009.

12. Madeira MC, Cruz Rizzolo RJ. Anatomía do dente. Sarvier. 7ma. Brasil. 2014:35 - 38

13. InfoStat. InfoStat versión 1.1. Grupo InfoStat, FCA, Universidad Nacional de Córdoba, Argentina 2002.

14. Souza V, Driessnarck M, Costa Mendes I. Revisión De Diseños de Investigación resaltantes para Enfermería. Parte 1: Diseños de Investigación Cuantitativa. Rev Latino-Am (Online) Enfermagem 2007 Maio-Junho; 15(3) Disponible en: Http://Scielo.Isciii.Es/Scielo.Php. Acceso 26 Jul. 2012.

15. Diamond M. Anatomía Dental. Noruega. México. 1992: 74-105.

16. Sobotta J. Atlas de Anatomía Humana. Madrid. Médica Panamericana 2006.

17. Alves N. Morphometric and Morphological Study of The Dental Roots of The Upper First Premolars. Int. J. Odontostomat. 2010;4(2):111-115.

18. Alves N. Morphometric Study of the Dental Roots of Permanent Lower Anterior Teeth in Brazilian Individuals. Int. J. Morphol. [Internet]. 2015 Mar [citado 2015 Ago 19]; 33(1): 210-212. Disponible en: http://www.scielo.cl/scielo.php?script=sci_arttext\&pid=S0717-95022015000100033\&lng=es. http:// dx.doi.org/10.4067/S0717-95022015000100033 
